Supporting Information

\title{
Biocatalytic Production of a Potent Inhibitor of Adipocyte Differentiation from Phloretin Using Engineered CYP102A1
}

Ngoc Anh Nguyen, ${ }^{\dagger, \neq}$ Jin Jang, ${ }^{\dagger, *}$ Thien-Kim Le, ${ }^{\dagger}$ Thi Huong Ha Nguyen, ${ }^{\dagger}$ Su-Min Woo,${ }^{\dagger}$ SuKyoung Yoo, ${ }^{\S}$ Young Ju Lee,,$\quad$ Ki Deok Park,, Soo-Jin Yeom, ${ }^{\dagger}$ Geun-Joong Kim, ${ }^{\S}$ Hyung-Sik Kang, ${ }^{* \dagger}$ and Chul-Ho Yun,,${ }^{*}$

${ }^{\dagger}$ School of Biological Sciences and Technology, Chonnam National University, 77 Yongbongro, Gwangju 61186, Republic of Korea

${ }^{\S}$ Department of Biological Sciences and Research Center of Ecomimetics, College of Natural Sciences, Gwangju 61186, Republic of Korea

" Gwangju Center, Korea Basic Science Institute, Gwangju 61186, Republic of Korea $\$$ These authors contributed equally to this work: Ngoc Anh Nguyen, Jin Jang,

*E-mail: chyun@jnu.ac.kr, Tel: +82-62-530-2194

*E-mail: kanghs@jnu.ac.kr, Tel: +82-62-530-2195 
Table of Contents

\begin{tabular}{|c|c|c|}
\hline Section & Contents & Page \\
\hline Experimental & $\begin{array}{l}\text { Chemicals } \\
\text { Screening of the CYP102A1 Libraries } \\
\text { LC-MS analysis } \\
\text { Characterization of a major metabolite of phloretin by NMR spectroscopy } \\
\text { Cell culture of mouse preadipocytes } \\
\text { Measurement of cell viability }\end{array}$ & $\begin{array}{l}\text { S3 } \\
\text { S3 } \\
\text { S4 } \\
\text { S5 } \\
\text { S6 } \\
\text { S6 }\end{array}$ \\
\hline Tables & $\begin{array}{l}\text { S1. Variation in the amino acid sequences of the CYP102A1 mutants } \\
\text { S2. Assignments of }{ }^{1} \mathrm{H} \text { and }{ }^{13} \mathrm{C} \text { NMR chemical shifts of phloretin and its major } \\
\text { metabolite } \\
\text { S3. Kinetic parameters of phloretin 3-hydroxylation by CYP102A1 mutants } \\
\text { S4. Production of 3-OH phloretin from phloretin by CYP102A1 mutants }\end{array}$ & $\begin{array}{l}\text { S7-10 } \\
\text { S11 } \\
\text { S12 } \\
\text { S13 }\end{array}$ \\
\hline Figures & $\begin{array}{l}\text { S1. HPLC traces of green apple extracts } \\
\text { S2. Deglycosylation of phlorizin by almond } \beta \text {-glucosidase } \\
\text { S3. Effect of temperature on the phlorizin deglycosylation } \\
\text { S4. Hydroxylation of phloretin catalyzed by CYP102A1 mutants } \\
\text { S5. pH-dependence of 3-OH phloretin formation by CYP102A1 M10 } \\
\text { S6. LC-MS analyses of the major product derived from the hydroxylation of phloretin } \\
\text { by the CYP102A1 mutants } \\
\text { S7. (A) Chemical Structure of the major metabolite M1 (3-OH phloretin) from } \\
\text { phloretin. (B) }{ }^{1} \mathrm{H} \text { NMR spectra of phloretin and its major metabolite, 3-OH phloretin } \\
\text { S8. (A) Expanded }{ }^{1} \mathrm{H} \text { NMR spectra of the metabolite, M1 (3-OH phloretin). (B) } \\
\text { Aromatic region in }{ }^{1} \mathrm{H} \text { NMR spectra of phloretin and its metabolite, M1 (3-OH } \\
\text { phloretin) } \\
\text { S9. (A) }{ }^{13} \mathrm{C} \text { NMR spectra of phloretin and its metabolite, M1 (3-OH phloretin). (B) } \\
\text { Aromatic region in }{ }^{13} \mathrm{C} \text { NMR spectra of phloretin and its major metabolite, M1 (3- } \\
\text { OH phloretin). } \\
\text { S10. One-pot synthesis of 3-OH phloretin from phlorizin by sequential reactions of } \beta \text { - } \\
\text { glucosidase and CYP102A1. } \\
\text { S11. Time-courses for the conversion of phloretin into 3-OH phloretin by recombinant } \\
\text { E. coli cells expressing CYP102A1 A42 mutant under the optimized conditions } \\
\text { S12. Effect of 3-OH phloretin and phloretin on cell viability of 3T3-L1 preadipocytes } \\
\text { S13. Inhibitory effect of OH phloretin on the expression of the adipogenic regulator } \\
\text { genes }\end{array}$ & $\begin{array}{l}\text { S15 } \\
\text { S16 } \\
\text { S17 } \\
\text { S18 } \\
\text { S19 } \\
\text { S20 } \\
\text { S21 }\end{array}$ \\
\hline References & References for Supporting Information & S27 \\
\hline
\end{tabular}




\section{Supplementary Experimental Section}

Materials. Phloretin (2',4',6'-trihydroxy-3-(4-hydroxyphenyl)-propiophenone), phlorizin (phloretin 2'- $\beta$-D-glucoside), $\beta$-nicotinamide adenine dinucleotide phosphate $\left(\mathrm{NADP}^{+}\right)$, glucose6-phosphate, glucose-6-phosphate dehydrogenase, $\beta$-glucosidase from almonds, 3-(4,5dimethylthiazol-2-yl)-5-(3-carboxymethoxyphenyl)-2-(4-sulfophenyl)-2H-tetrazolium (MTS), phenazine methosulfate (PMS), insulin, 1-isobutyl-3-methylxanthine (IBMX), and dexamethasone were purchased from Sigma-Aldrich. Acetonitrile, methanol, and other chemicals used in this study were of high quality and used without further purification.

Two kinds of green apple powder were obtained from local companies, which were originally produced by KMD Project SP.zo.o (Leszno, Poland) and Shaanxi Sciphar Natural Products Co (Xian, China). One gram of the apple powder was added to $10 \mathrm{~mL}$ water, mixed, sonicated for $30 \mathrm{~min}$, and centrifuged at $3,000 \mathrm{~g}$ and $4{ }^{\circ} \mathrm{C}$ for $30 \mathrm{~min}$. Upper phase $(1 \mathrm{~mL})$ was extracted with ethyl acetate $(5 \mathrm{~mL})$, dried with nitrogen gas, and mixed with mobile phase to inject to HPLC.

Screening of the CYP102A1 Libraries. Randomized libraries were transformed into $E$. coli XL1-Blue. E. coli cells that expressed the CYP102A1 mutants were spread on Luria-Bertani (LB) broth agar expression plates and incubated at $37^{\circ} \mathrm{C}$ for $16 \mathrm{~h}$. Then, the colonies of $0.3 \sim 0.5$ $\mathrm{mm}$ were stored at $4^{\circ} \mathrm{C}$ for $1 \sim 2$ weeks until blue colonies appeared. This colorimetric (blue) colony-based method was adopted for primary screening of the mutants. ${ }^{1}$ Blue colonies, which seem to be resulted from indigo formation, ${ }^{1,2}$ showed higher expression levels of $\mathrm{P} 450$ than those 
of white colonies. The P450 expression levels of blue colonies were more than $100 \mathrm{nM}$ and those of white colonies were less than $20 \mathrm{nM}$. Thus, first screening to select blue colonies was done to find mutants with higher expression of P450.

LB agar expression plates contained $25 \mathrm{~g} \mathrm{~L}^{-1} \mathrm{LB}$ broth (BD Biosciences, San Jose, CA), $15 \mathrm{~g} \mathrm{~L}^{-1}$ Bacto agar (BD Biosciences), and $100 \mu \mathrm{g} \mathrm{mL}^{-1}$ ampicillin. No additives, including indole, isopropyl- $\beta$-D-1-thiogalactopyranoside (IPTG), or $\delta$-aminolevulinic acid, were added to the plates. Approximately 500 blue colored colonies were transferred into 96-deep-well plates that contained $0.3 \mathrm{~mL}$ of LB media and $100 \mu \mathrm{g} \mathrm{mL} \mathrm{m}^{-1}$ ampicillin. The bacteria were initially cultured for $8 \mathrm{~h}$ at $37^{\circ} \mathrm{C}$ and $450 \mathrm{rpm}$ (HT-MegaGrow incubator; Bioneer Co., Daejeon, Korea). Aliquots of the cell cultures $(30 \mu \mathrm{L})$ were transferred to single wells of 96-deep-well plates filled with $0.5 \mathrm{~mL}$ of Terrific Broth expression media containing additives (10 $\mu \mathrm{M}$ IPTG, $0.5 \mathrm{mM} \delta$-aminolevulinic acid) and ampicillin. These aliquots were cultured for $17 \mathrm{~h}$ at $30^{\circ} \mathrm{C}$ and $450 \mathrm{rpm}$. The whole-cell activities of the mutants were measured by using phloretin as a substrate. The cells were collected by centrifugation at $3500 \mathrm{rpm}$ for $10 \mathrm{~min}$ at $4^{\circ} \mathrm{C}$ and frozen at $-20^{\circ} \mathrm{C}$. Cell pellets were resuspended in $300 \mu \mathrm{L}$ of a $100 \mathrm{mM}$ phosphate buffer (pH 7.4) that contained $10 \mathrm{mM} \mathrm{MgCl}_{2}$. Phloretin (100 $\mu \mathrm{M})$ was added to initiate the reaction and the reaction mixtures were incubated for $60 \mathrm{~min}$ at $37^{\circ} \mathrm{C}$, and the reaction was stopped with $0.60 \mathrm{~mL}$ of ice-cold ethyl acetate. The formation rate of 3-OH phloretin was determined by HPLC, as described at Experimental Section. 
Selected four mutants were expressed in the E. coli strain DH5 $\mathrm{F}^{\prime}$-IQ and partially purified as lysate. ${ }^{3}$ CYP102A1 concentrations were determined from CO-difference spectra using $\varepsilon=91$ $\mathrm{mM} / \mathrm{cm} .{ }^{4}$ For the WT and mutants, a typical culture yielded 300 to $700 \mathrm{nM}$ P450.

LC-MS analysis. To identify the phloretin metabolite formed by the CYP102A1 mutants, LC-MS analysis of the metabolites was performed for comparison of LC profiles and fragmentation patterns with those of the authentic phloretin compound. M10 was incubated with a $200 \mu \mathrm{M}$ phloretin at $37^{\circ} \mathrm{C}$ for $1 \mathrm{~h}$ in the presence of an NADPH-generating system. The reactions were stopped by adding a 2-fold excess of ice-cold ethyl acetate. After centrifugation, the supernatant from each incubated reaction mixture was removed and evaporated to dryness. The reaction residue was solubilized with $180 \mu \mathrm{L}$ of mobile phase by vortex mixing and sonication for $30 \mathrm{~s}$. An aliquot $(5 \mu \mathrm{L})$ of this solution was injected onto the LC column (Shim-pack VP-ODS column, $2.0 \mathrm{~mm}$ id. $\times 250 \mathrm{~mm}$, Shimadzu Corporation, Japan). LC-MS analysis was approved out in electrospray ionization (negative) mode on a Shimadzu LCMS-2010 EV system with LCMS solution software. Mobile phase A was water containing $0.1 \%$ formic acid and $0.5 \%$ methanol; mobile phase B was $100 \%$ acetonitrile. Reaction products and substrate were eluted at a flow rate of $0.10 \mathrm{~mL} \mathrm{~min}^{-1}$ using an increasing stepwise gradient of acetonitrile (mobile phase B) from 9 to 100\% (v/v) over $37.5 \mathrm{~min}: 0-11 \mathrm{~min}, 9 \%$ acetonitrile; $11-13 \mathrm{~min}, 15 \%$ acetonitrile; $13-20 \mathrm{~min}$, $17 \%$ acetonitrile; $20-37 \mathrm{~min}, 60 \% ; 37-37.5 \mathrm{~min}, 100 \%$ acetonitrile. The retention times for a major metabolite and phloretin were 39.7 and $42.2 \mathrm{~min}^{-1}$, respectively. Interface and detector voltages were each $4.4 \mathrm{kV}$ and $1.5 \mathrm{kV}$, respectively. The nebulization gas flow was set at $1.5 \mathrm{~L} \mathrm{~min}^{-1}$. The 
interface, curve desolvation line, and heat block temperatures were 250,250 , and $200^{\circ} \mathrm{C}$, respectively.

Characterization of a major metabolite of phloretin by NMR spectroscopy. After the major metabolite of phloretin was produced by the M10, separated by HPLC, and collected in an ice bucket, and the solvent was removed by freezer-dryer. NMR investigations were performed at ambient temperature on a Varian VNMRS 600 MHz NMR spectrometer equipped with a carbonenhanced cryogenic probe (Korea Basic Science Institute, Gwangju, Korea). Methanol-d 4 was used as solvent, and chemical shifts for proton NMR spectra were measured in parts per million (ppm) relative to tetramethylsilane. All of the NMR experiments were performed with standard pulse sequences in VNMRJ (v. 3.2) library and processed with the same software.

Cell culture of mouse preadipocytes. 3T3-L1 mouse preadipocytes were purchased from the American Type Culture Collection (Manassas, VA, USA) and maintained in Dulbecco modified Eagle Medium (DMEM, Gibco, Thermo Fisher Scientific) supplemented with 10\% newborn calf serum and $1 \%$ Antibiotics-Antimyotic (Gibco) at $37^{\circ} \mathrm{C}$ in $5 \% \mathrm{CO}_{2}$-humidified atmosphere.

Measurement of cell viability. 3T3-L1 cells were seeded in 96-well plates at a density of $1 \times 10^{4}$ cells/well and cultured for $12 \mathrm{~h}$, then the cells were treated with various concentrations of phloretin and 3-OH phloretin for 8 days. Cell viability was analysed using MTS assay (CellTiter 96 AQueous Non-Radioactive Cell Proliferation Assay, Promega, Fitchburg, Wisconsin, USA), as 
described in the complete protocol. The absorbance was measured at $490 \mathrm{~nm}$ using an automated plate reader (SoftMax Pro version 5, Molecular Devices, Sunnyvale, CA, USA). 
Table S1. Variation in the amino acid sequences of the CYP102A1 mutants

\begin{tabular}{|c|c|c|}
\hline Mutant & Mutated Amino Acid Residues & Reference \\
\hline Wild-type & & (5) \\
\hline M2 & A264G & (3) \\
\hline M3 & F87A/A264G & (3) \\
\hline M4 & $\mathrm{R} 47 \mathrm{~L} / \mathrm{Y} 51 \mathrm{~F}$ & (3) \\
\hline M5 & R47L/Y51F/A264G & (3) \\
\hline M6 & R47L/Y51F/F87A & (3) \\
\hline M7 & R47L/Y51F/F87A/A264G & (3) \\
\hline M8 & A74G/F87V/L188Q & (3) \\
\hline M9 & R47L/L86I/L188Q & (3) \\
\hline M10 & R47L/F87V/L188Q & (3) \\
\hline M11 & R47L/F87V/L188Q/E267V & (3) \\
\hline M12 & R47L/L86I/L188Q/E267V & (3) \\
\hline M13 & R47L/L86I/F87V/L188Q & (3) \\
\hline
\end{tabular}




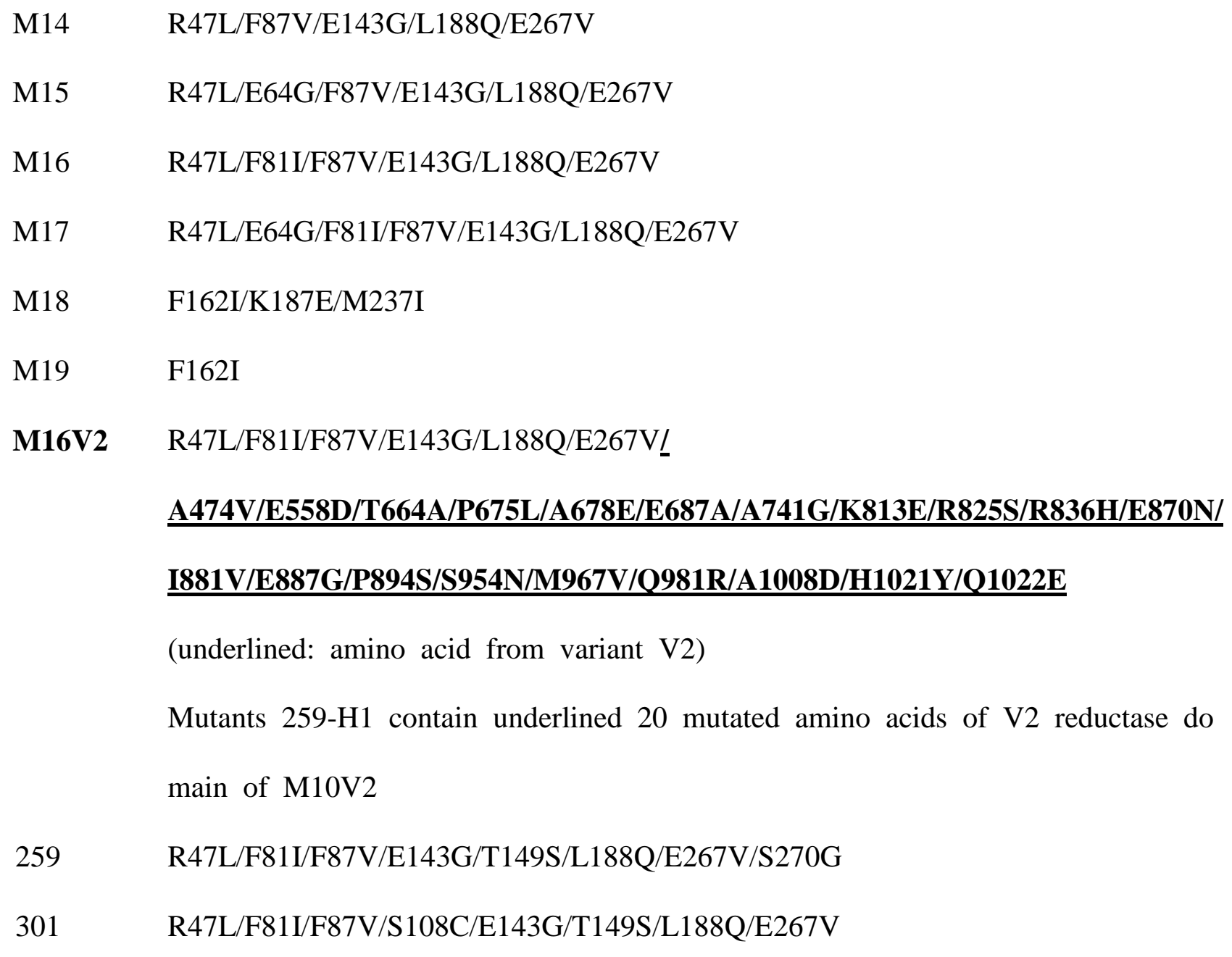




$\begin{array}{ll}306 & \text { R47L/F81I/F87V/M112T/E143G/L188Q/E267V/M417T } \\ 326 & \text { R47L/F81I/F87V/K113E/E143G/T152S/L188Q/F261L/E267V } \\ 380 & \text { R47L/F81I/F87V/L103F/D136G/E143G/N159S/L188Q/E267V } \\ 387 & \text { F11L/R47L/F811/F87V/Q110P/E143G/L188Q/R190Q/E267V } \\ 389 & \text { D23G/R47L/F81I/D84N/F87V/E143G/G154S/M185V/L188Q/E267V } \\ 413 & \text { R47L/F81I/F87V/Q128R/E143G/L188Q/E267V/L287S/K309R/S383C } \\ 416 & \text { R47L/S72C/F81I/F87V/S108G/E143G/F158L/L188Q/M212V/E267V/E344D } \\ \text { B3 } & \text { R47L/F81I/F87V/E143G/I153T/K187Q/ L188Q/N192I/K202Q/E267V } \\ \text { B9 } & \text { R47L/F81I/F87V/E143G/L188Q/K224R/E267V/G271D/V281A/Q403K } \\ \text { C7 } & \text { R47L/K59N/F81I/F87V/E143G/L188Q/G240E/E267V/S383R } \\ \text { D1 } & \text { R47L/F81I/F87V/Y115C/E143G/I174S/L188Q/E267V/T268A/Y313F } \\ \text { D8 } & \text { R47L/F81I/F87V/E143G/L188Q/E267V/Y334C/A335V/D369G } \\ \text { D12 } & \text { R47L/F81I/F87V/E143G/L188Q/Q206R/E267A/V297A/K336E } \\ \text { E7 } & \text { R47L/Q73R/F81I/F87V/S108N/E143G/L188Q/I220M/E267V } \\ & \end{array}$




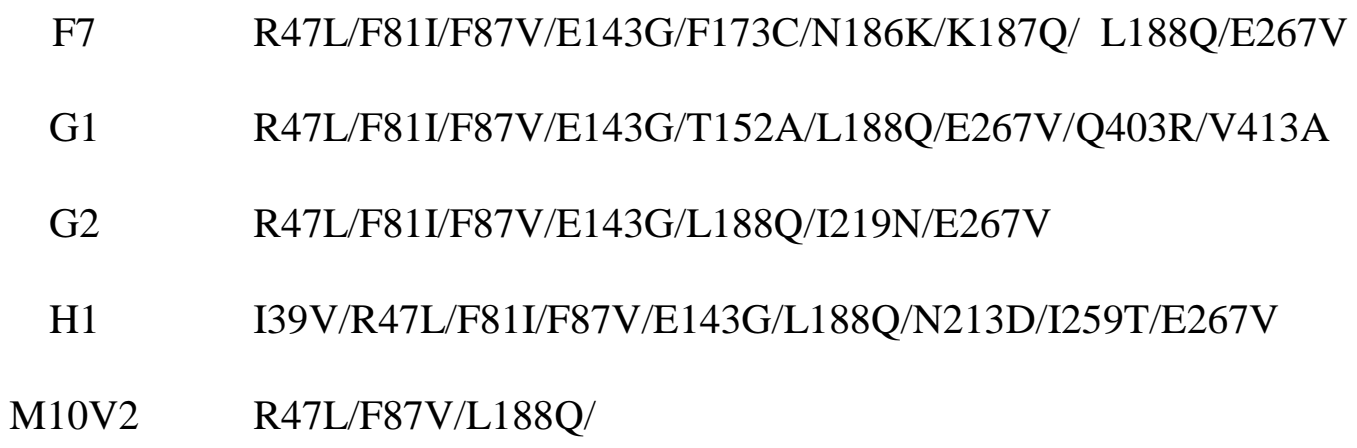

This work

This work

This work

This work 
Table S2. Assignments of ${ }^{1} \mathrm{H}$ and ${ }^{13} \mathrm{C}$ NMR chemical shifts of phloretin and its major metabolite.

\begin{tabular}{|c|c|c|}
\hline Position & $\begin{array}{c}\delta_{\mathrm{C}} \\
{ }^{13} \mathrm{C}(\delta), \mathrm{ppm}\end{array}$ & $\begin{array}{c}\delta_{\mathrm{H}} \\
{ }^{1} \mathrm{H}(\delta), \mathrm{ppm}\end{array}$ \\
\hline$\beta^{\prime}$ & 206.5 & \\
\hline$\alpha$ & 47.4 & $3.262(2 \mathrm{H}, \mathrm{m})$ \\
\hline$\beta$ & 31.8 & $2.793(2 \mathrm{H}, \mathrm{m})$ \\
\hline 1 & 134.9 & \\
\hline 2 & 116.7 & $\begin{array}{c}6.666(1 \mathrm{H}, \mathrm{d}, \mathrm{J}=2.0 \mathrm{~Hz}, \\
\text { partially overlapped with } \\
\text { a wing of } 5-\mathrm{H} \text { proton } \\
\text { doublet })\end{array}$ \\
\hline 3 & 146.3 & \\
\hline 4 & 144.5 & \\
\hline 5 & 116.4 & $6.662(1 \mathrm{H}, \mathrm{d}, \mathrm{J}=8.0 \mathrm{~Hz})$ \\
\hline 6 & 120.8 & $\begin{array}{c}6.541(1 \mathrm{H}, \mathrm{dd}, \mathrm{J}=2.0 \mathrm{~Hz}, \\
8.0 \mathrm{~Hz})\end{array}$ \\
\hline $1^{\prime}$ & 105.4 & \\
\hline $2^{\prime}, 6^{\prime}$ & 166.0 & \\
\hline $3^{\prime}, 5^{\prime}$ & 95.9 & $5.807(2 \mathrm{H}, \mathrm{s})$ \\
\hline $4^{\prime}$ & 166.3 & \\
\hline
\end{tabular}


Table S3. Kinetic parameters of phloretin 3-hydroxylation by CYP102A1 mutants.

\begin{tabular}{ccccc}
\hline CYP102A1 & $k_{\text {cat }}\left(\mathrm{min}^{-1}\right)$ & $K_{\mathrm{m}}(\mu \mathrm{M})$ & $k_{\text {cat }} / K_{\mathrm{m}}$ & $\begin{array}{c}\text { Relative catalytic } \\
\text { efficiency }\end{array}$ \\
\hline M10 & $20 \pm 1$ & $59 \pm 8$ & $0.34 \pm 0.05$ & 1 \\
M16 & $6.5 \pm 0.8$ & $65 \pm 16$ & $0.10 \pm 0.03$ & 0.29 \\
M16V2 & $6.9 \pm 0.4$ & $38 \pm 6$ & $0.18 \pm 0.03$ & 0.53 \\
M10V2 & $30 \pm 4$ & $56 \pm 12$ & $0.54 \pm 0.14$ & 1.6 \\
A29 & $41 \pm 2$ & $28 \pm 4$ & $1.4 \pm 0.2$ & 4.1 \\
A32 & $55 \pm 8$ & $45 \pm 21$ & $1.2 \pm 0.6$ & 3.5 \\
A33 & $41 \pm 3$ & $40 \pm 9$ & $1.0 \pm 0.2$ & 2.9 \\
A42 & $420 \pm 170$ & $740 \pm 360$ & $0.60 \pm 0.38$ & 1.8 \\
\hline
\end{tabular}


Table S4. Production of 3-OH phloretin from phloretin by CYP102A1 mutants.

\begin{tabular}{|c|c|c|}
\hline CYP102A1 & Conversion( $\%)^{[\mathrm{a}]}$ & Selectivity $(\%)^{[b]}$ \\
\hline M10 & 61 & 96 \\
\hline M16 & 19 & 95 \\
\hline M16V2 & 25 & 95 \\
\hline A29 & 49 & 96 \\
\hline A 32 & 84 & 95 \\
\hline A33 & 82 & 95 \\
\hline A42 & 94 & 96 \\
\hline \multicolumn{3}{|c|}{$\begin{array}{l}{\left[\mathrm{a},[\mathrm{b}] \mathrm{HPLC} \text { was used to determine the }{ }^{[\mathrm{a}]} \text { conversion yield and }{ }^{[\mathrm{b}]} \text { selectivity of } 3-\mathrm{OH} \text { phloretin }\right.} \\
\text { production. The reaction mixtures of } \mathrm{P} 450(0.40 \mu \mathrm{M}) \text {, phloretin }(0.20 \mathrm{mM}) \text { and an NADPH } \\
\text { regeneration system in a } 100 \mathrm{mM} \text { potassium phosphate buffer }(\mathrm{pH} 7.4) \text { were incubated at } \\
37^{\circ} \mathrm{C} \text { for } 2 \mathrm{~h} \text {. The results are reported as the mean of triplicate experiments. }\end{array}$} \\
\hline
\end{tabular}




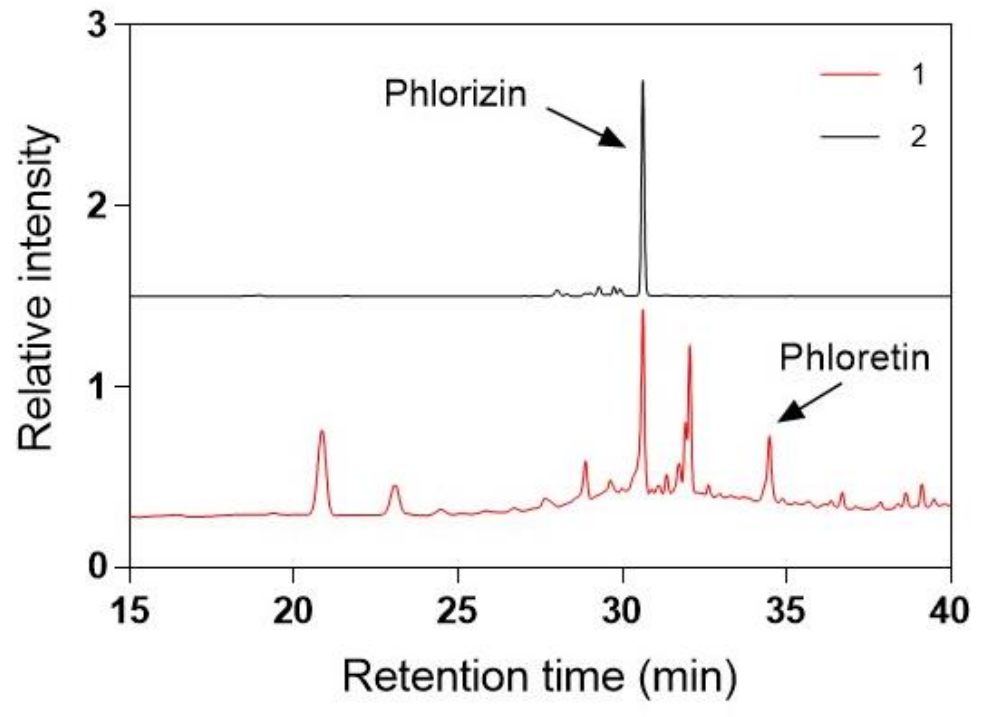

Figure S1. HPLC traces of green apple extracts. The apple powder was obtained from two commercial sources. HPLC chromatograms were identified by comparing their retention times with those of the following standards: phlorizin $\left(t_{\mathrm{R}}=30.5 \mathrm{~min}\right)$ and phloretin $\left(t_{\mathrm{R}}=34.3 \mathrm{~min}\right)$. 

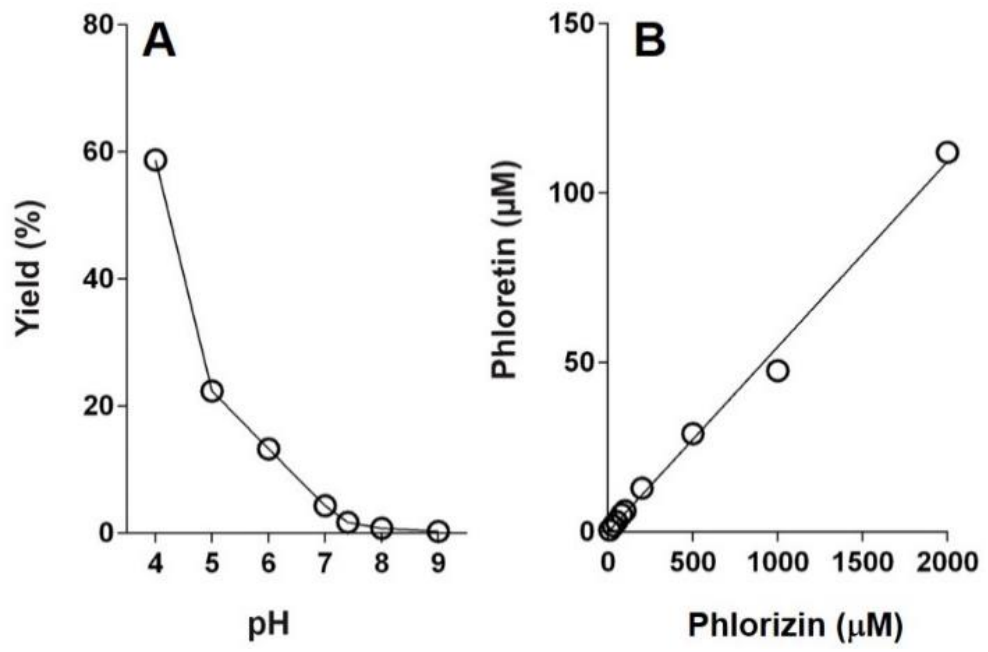

Figure S2. Deglycosylation of phlorizin by almond $\beta$-glucosidase. (A) $\mathrm{pH}$ dependence of phlorizin deglycosylation was examined from $\mathrm{pH} 4$ to $\mathrm{pH}$ 9. (B) The effect of substrate concentration from $10 \mu \mathrm{M}$ to $2 \mathrm{mM}$ on the product formation was examined at $\mathrm{pH} 4$ for 30 min reaction. 


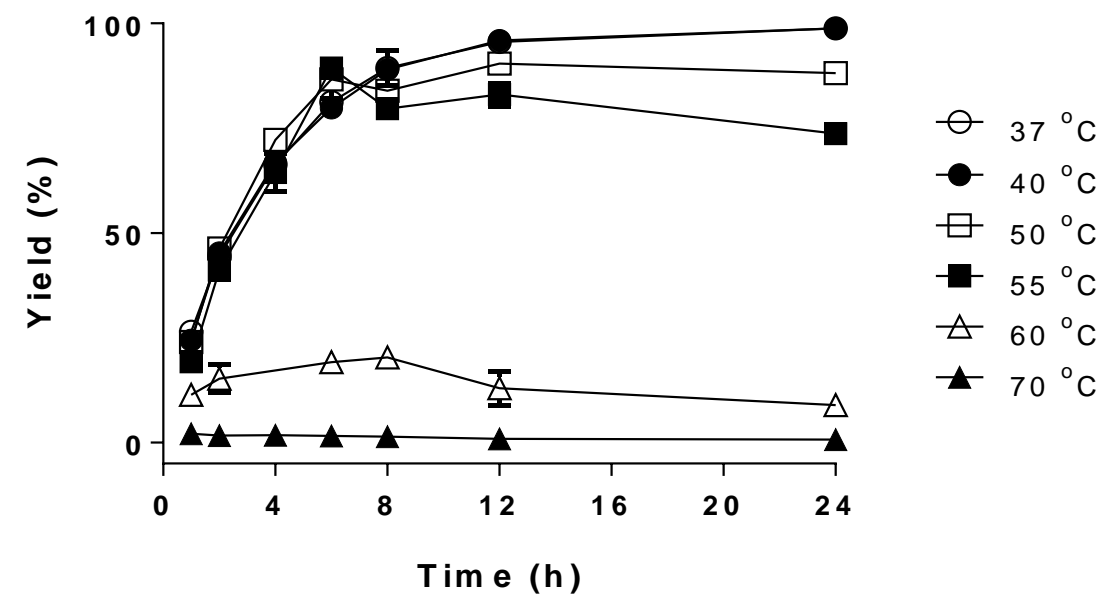

Figure S3. Effect of temperature on the phlorizin deglycosylation. Effect of temperature on the phlorizin deglycosylation at $\mathrm{pH} 4.0$ in the range of $37 \sim 70^{\circ} \mathrm{C}$ was tested with 50 $\mu \mathrm{M}$ substrate and $\beta$-glucosidase (5 units) during indicated time. 

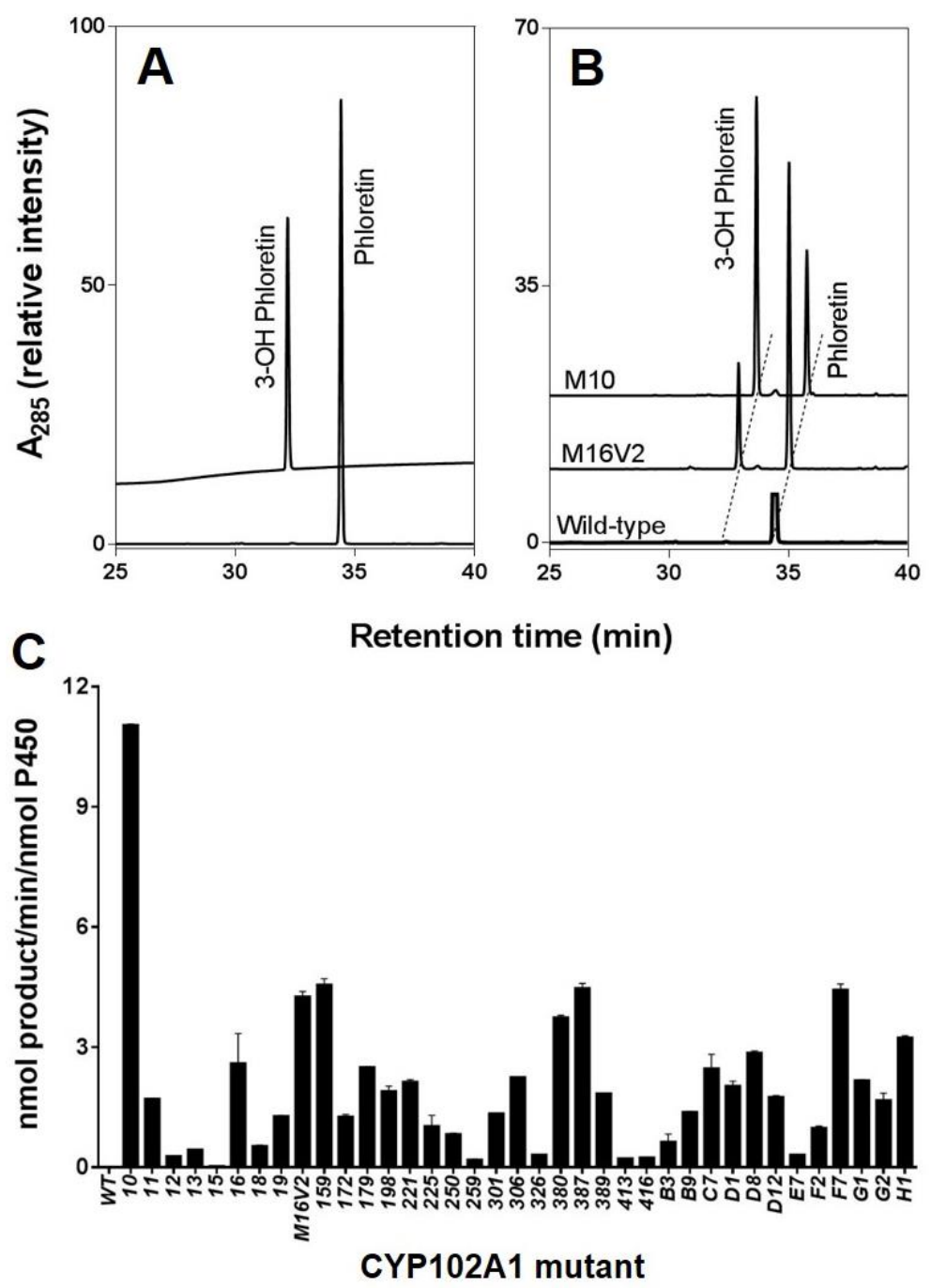

Figure S4. Hydroxylation of phloretin catalyzed by CYP102A1 mutants. The peaks of standards (A) and reaction mixtures (B) of HPLC chromatograms were identified by comparing their retention times with those of the following standards: authentic 3-OH phloretin $\left(t_{\mathrm{R}}=32.5 \mathrm{~min}\right)$ and phloretin $\left(t_{\mathrm{R}}=34.7 \mathrm{~min}\right)$. (C) Rates of $3-\mathrm{OH}$ phloretin production by the 46 mutants are presented as the mean \pm the SEM of duplicate measurements. 


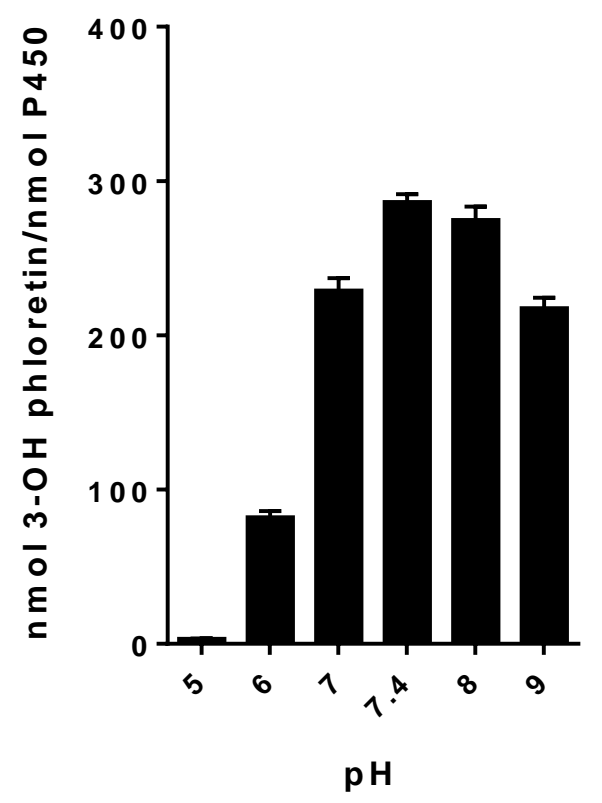

Figure S5. $\mathrm{pH}$ dependence of 3-OH phloretin formation by CYP102A1 mutant M10. Effect of $\mathrm{pH}$ on the catalytic activity of CYP102A1 for 3-OH phloretin formation was investigated using $200 \mu \mathrm{M}$ phloretin substrate in a $\mathrm{pH}$ range of $5 \sim 9$ for $1 \mathrm{~h}$ at $37^{\circ} \mathrm{C}$. Buffers of sodium acetate $(10 \mathrm{mM})$ and potassium phosphate $(100 \mathrm{mM})$ were used for $\mathrm{pH}$ 5 and $\mathrm{pH} 6-9$, respectively. 
( A ) TIC
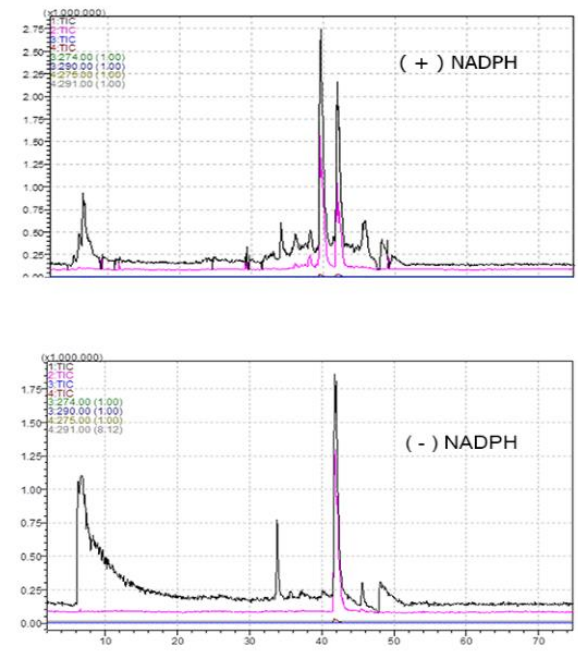

Event\#: 1 Scan (E+) Ret. Time : 39.667 Scan\#: 2261

( B ) Product
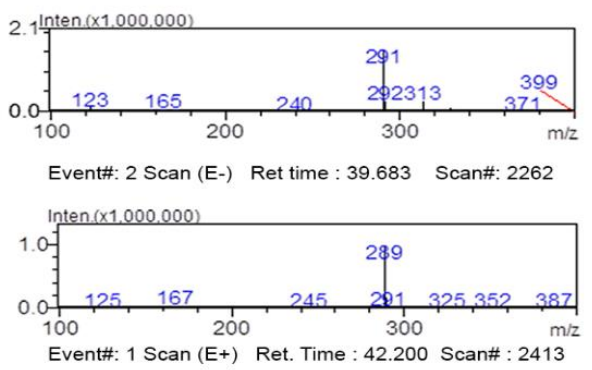

(C) Substrate
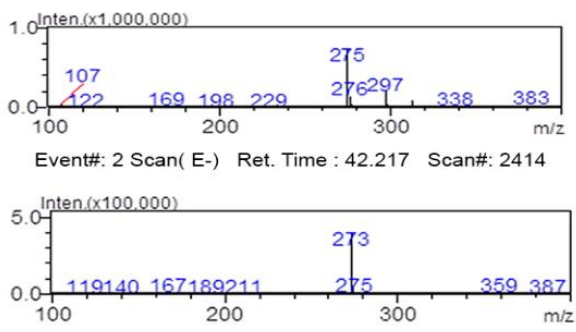

Figure S6. LC-MS analyses of the major product derived from the hydroxylation of phloretin by the CYP102A1 mutants. The figures show data from HPLC and LC-MS studies of phloretin after its enzymatic turnover by the CYP102A1 mutant M10. (A) The total ion current (TIC) description of the substrate phloretin and 3-OH phloretin product generated by M10 was shown. Extracted ion chromatograms were contracted from the incubation of phloretin with the M10 in the absence and presence of NADPH and the peaks of phloretin and 3-OH phloretin are shown at 42.2 and $39.7 \mathrm{~min}$, respectively. (B) The calculated mass for the major metabolite was 291 in scan (E+) and 289 in scan (E-), respectively. (C) The calculated mass for the substrate phloretin was 275 in scan (E+) and 273 in scan (E-), respectively. The MS spectra demonstrate that the protonated molecular ions of for the major metabolite (B) and phloretin (C) were 290 and 274, respectively. 
(A)

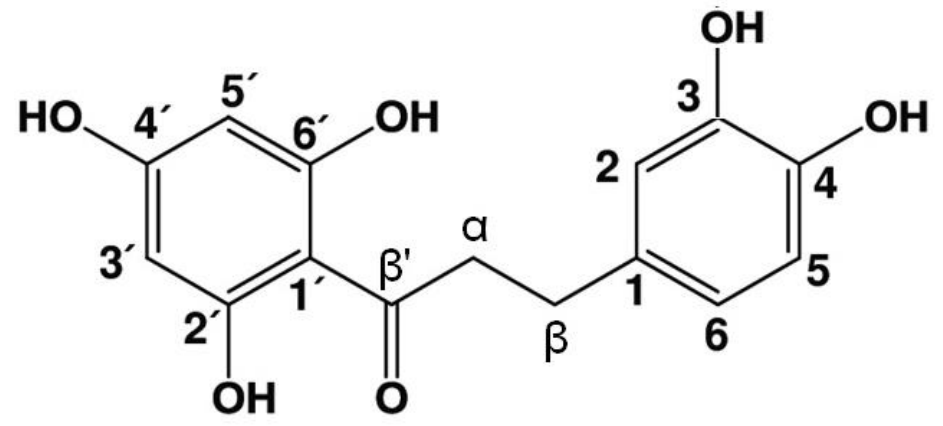

(B)
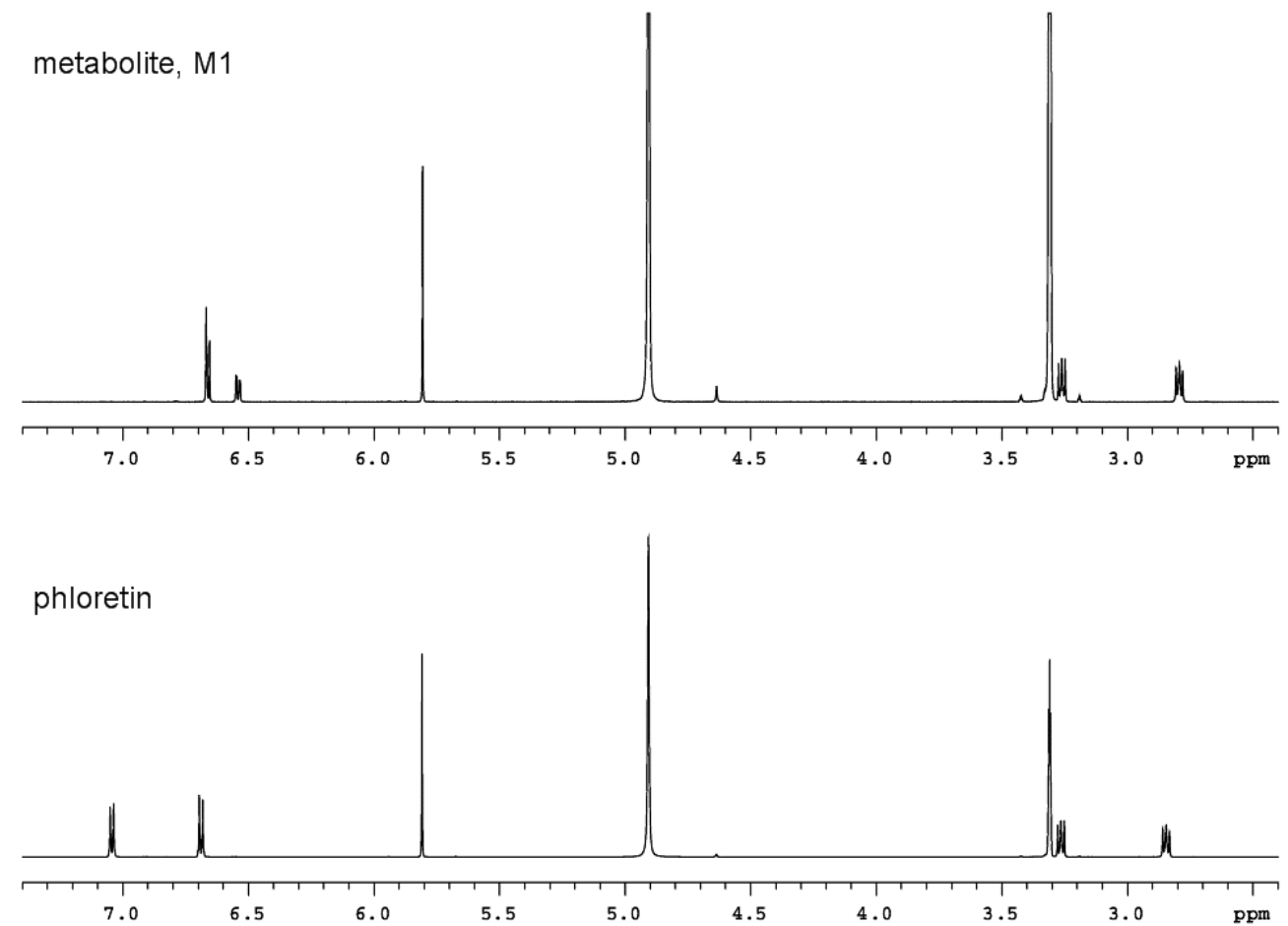

Figure S7. (A) Chemical structure of the major metabolite M1 (3-OH phloretin) from phloretin. (B) ${ }^{1} \mathrm{H}$ NMR spectra of phloretin and its major metabolite, 3-OH phloretin. 
(A)
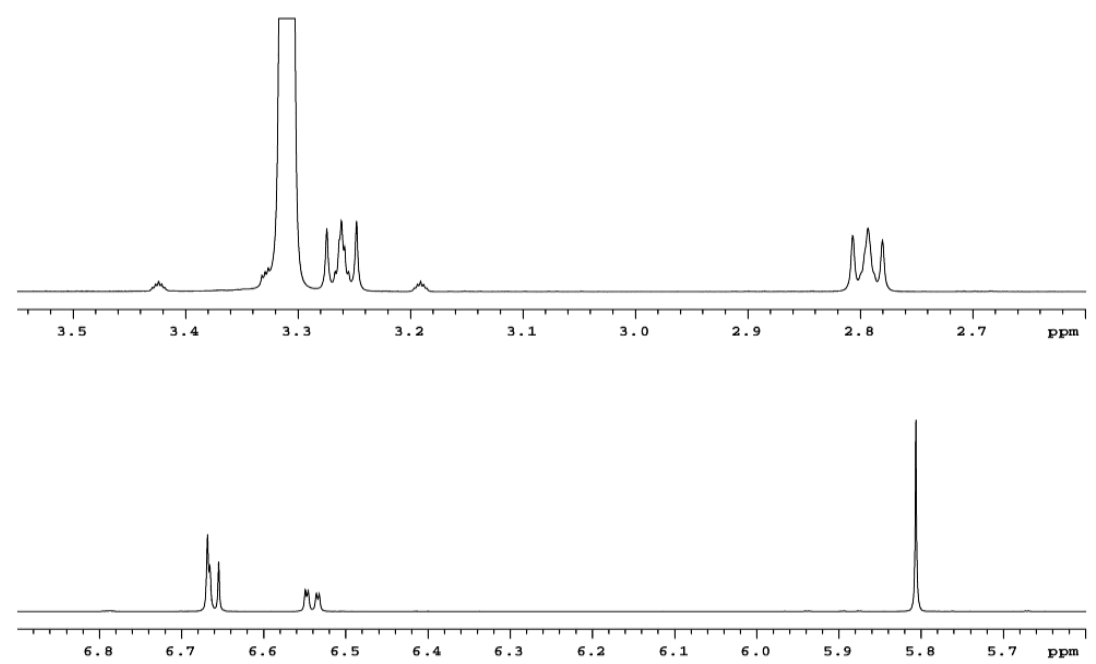

(B)

metabolite, M1
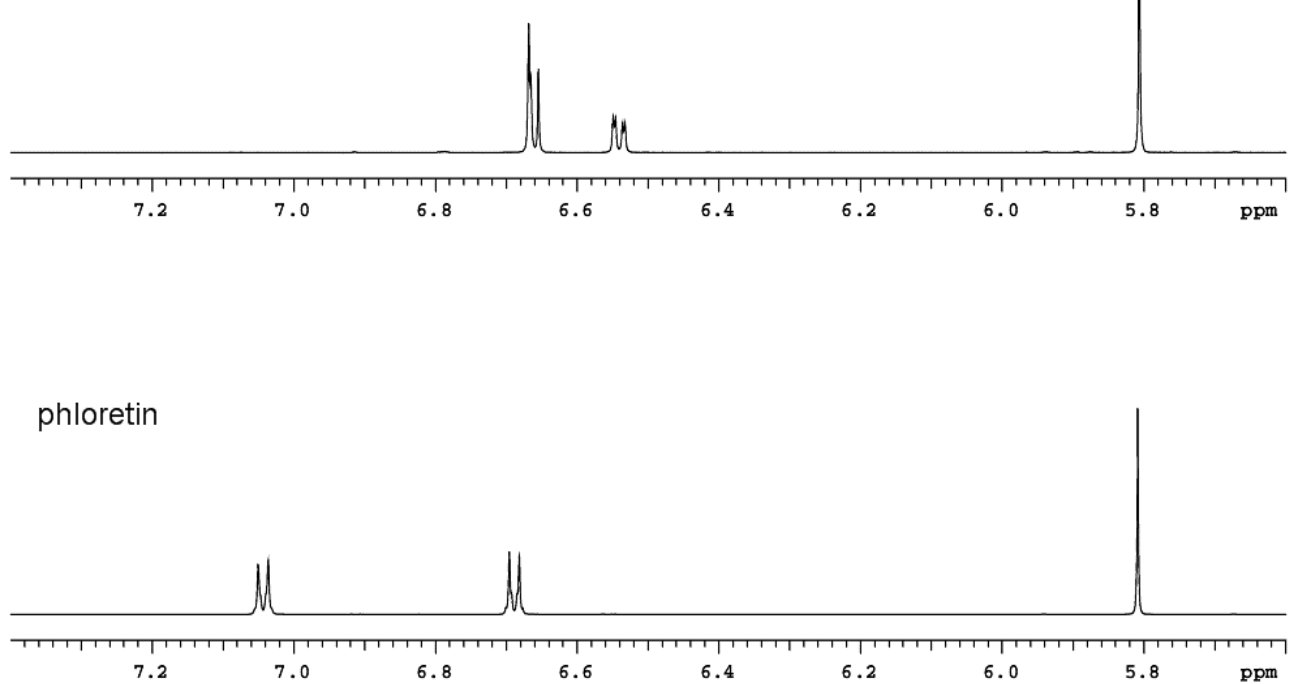

Figure S8. (A) Expanded ${ }^{1} \mathrm{H}$ NMR spectra of the metabolite, M1 (3-OH phloretin). (B) Aromatic region in ${ }^{1} \mathrm{H}$ NMR spectra of phloretin and its metabolite, M1 (3-OH phloretin). 
(A)

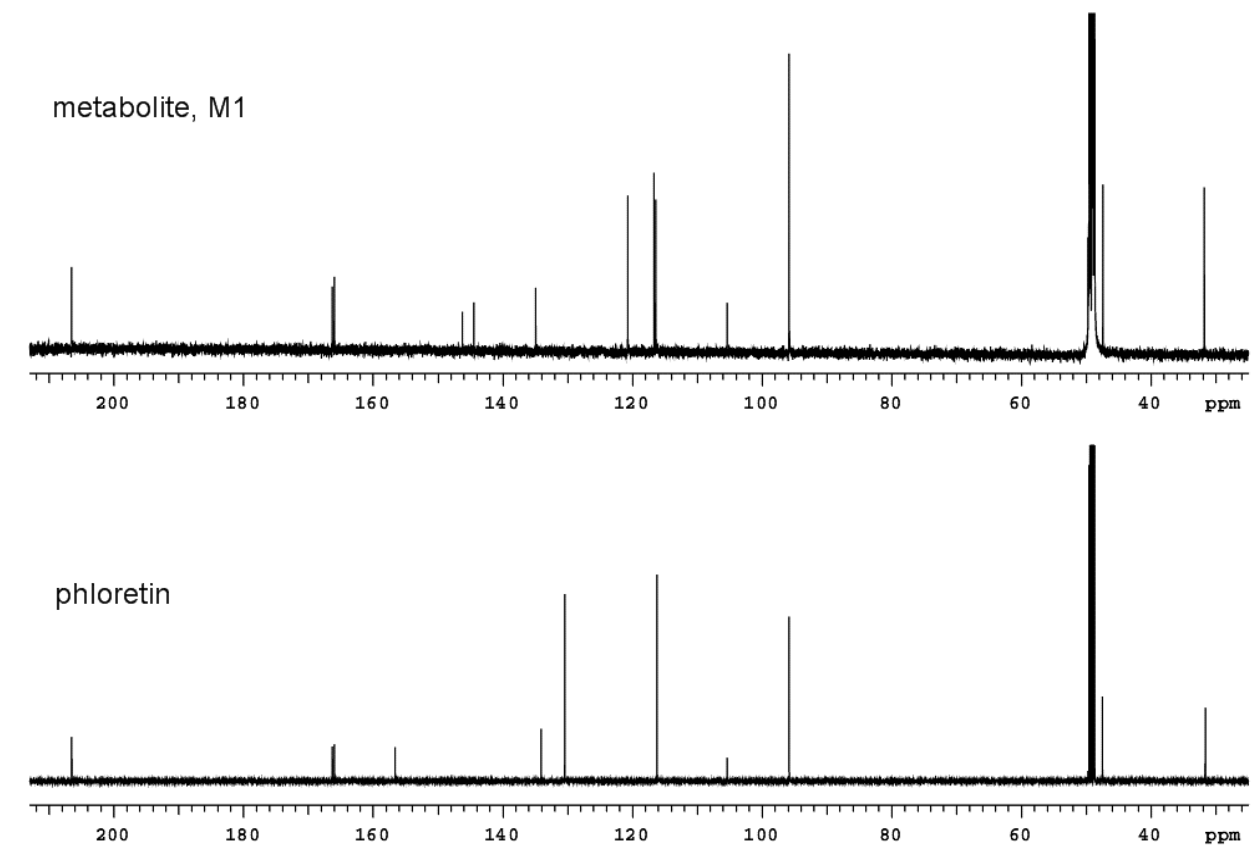

(B)

metabolite, M1

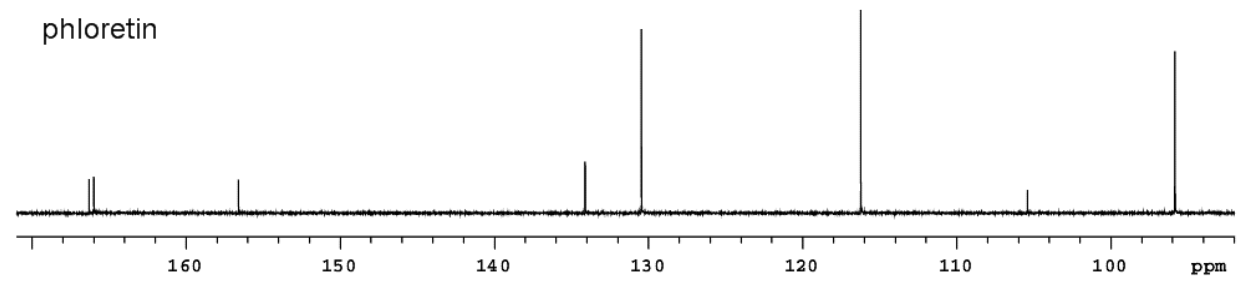

Figure S9. (A) ${ }^{13} \mathrm{C}$ NMR spectra of phloretin and its metabolite, M1 (3-OH phloretin). (B) Aromatic region in ${ }^{13} \mathrm{C}$ NMR spectra of phloretin and its major metabolite, M1 (3$\mathrm{OH}$ phloretin). 

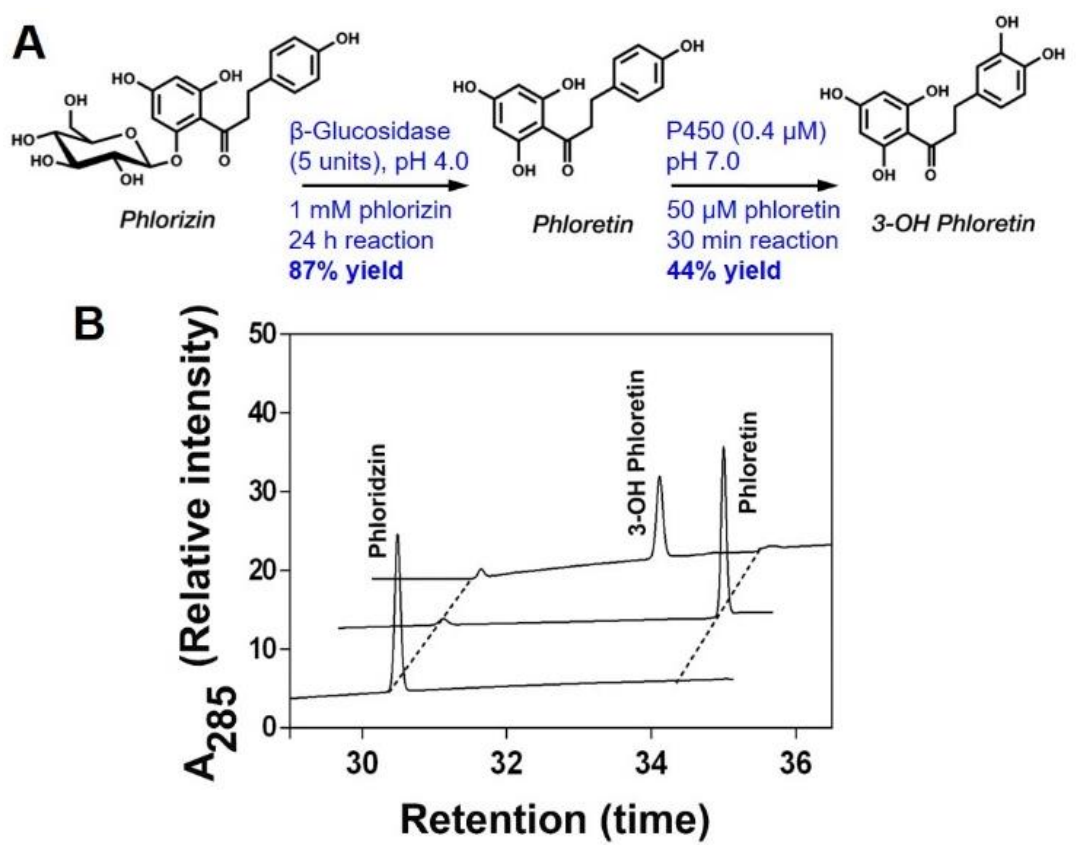

Figure S10. One-pot synthesis of 3-OH phloretin from phlorizin by sequential reactions of $\beta$-glucosidase and CYP102A1. (A) Chemical structures with reaction conditions for sequential reactions of $\beta$-glucosidase and CYP102A1. (B) HPLC chromatographs of starting material phlorizin, intermediate phloretin, and final product 3-OH phloretin at experimental conditions shown at (A). 


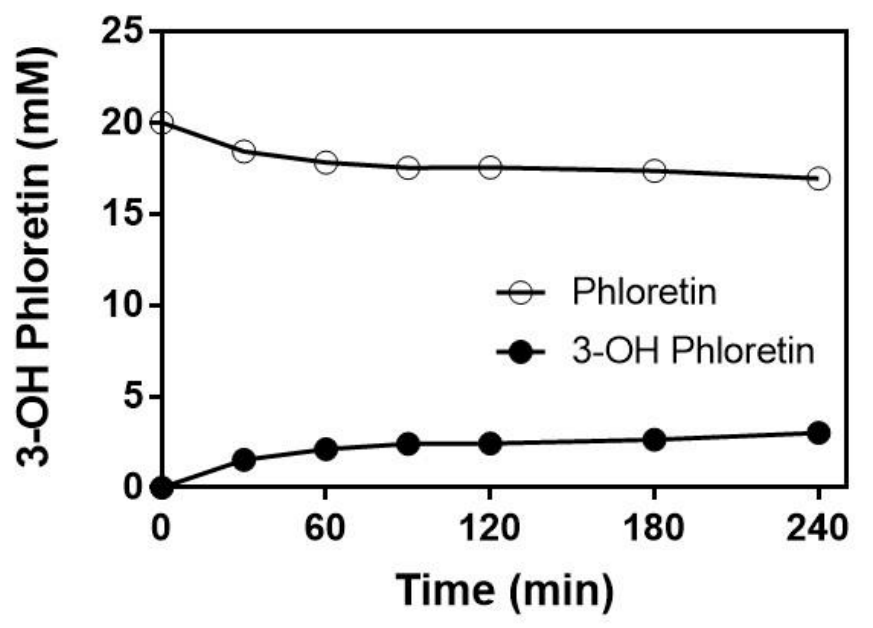

Figure S11. Time-courses for the conversion of phloretin into 3-OH phloretin by recombinant E. coli cells expressing CYP102A1 A42 mutant under the optimized conditions: phloretin $(\circ)$ and 3-OH phloretin $(\bullet)$. The reactions were performed in 100 $\mathrm{mM}$ potassium phosphate (pH 7.4) buffer containing $15 \mathrm{~g} \mathrm{~L}^{-1}$ cells and $20 \mathrm{mM}$ phloretin at $37^{\circ} \mathrm{C}$ for $240 \mathrm{~min}$. Data are presented as the mean \pm the SD of triplicate measurements. 


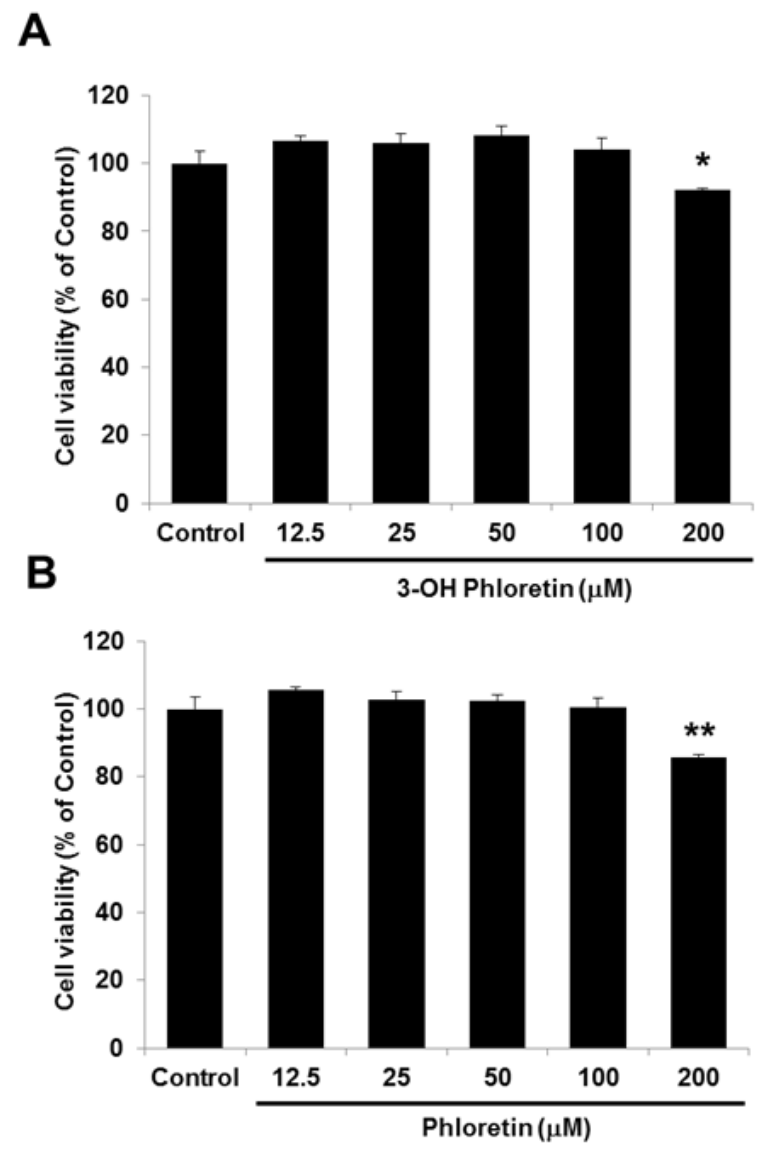

Figure S12. Effect of 3-OH phloretin and phloretin on cell viability of 3T3-L1 preadipocytes. The cell viability of 3T3-L1 preadipocytes was measured by MTS assay after treatment with $3-\mathrm{OH}$ phloretin (A) and phloretin (B) at each concentration $\left({ }^{*} p<\right.$ $0.05 ; * * p 0.01)$. 

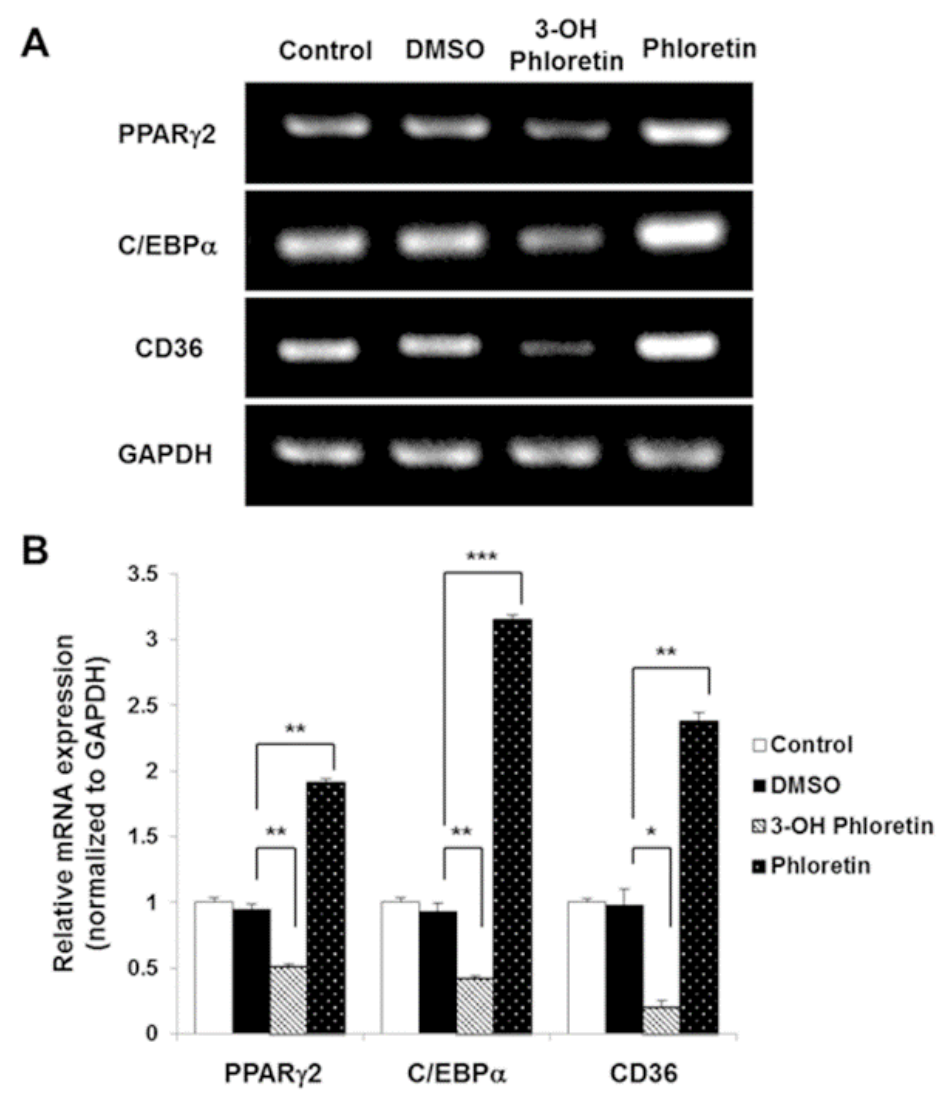

Figure S13. Inhibitory effect of 3-OH phloretin on the expression of the adipogenic regulator genes. (A) Gene expression was analysed by RT-PCR after 8 days of DMI induction. (B) Densities of RT-PCR bands were quantified using ImageJ. The data represent the mean \pm the SEM of three independent experiments $(* p<0.05 ; * * p<0.01$; $* * * p<0.001)$. 


\section{References for Supporting Information}

(1) Park, S. H.; Kim, D. H.; Kim, D.; Kim, D. H.; Jung, H. C.; Pan, J. G.; Ahn, T.; Kim, D.; Yun, C. H. Engineering Bacterial Cytochrome P450 (P450) BM3 into a Prototype with Human P450 Enzyme Activity using Indigo Formation. Drug Metab. Dispos. 2010, 38 (5), 732-739. doi: $10.1124 /$ dmd.109.030759

(2) Nakamura, K.; Martin, M. V.; Guengerich, F. P. Random mutagenesis of human cytochrome p4502A6 and screening with indole oxidation products. Arch. Biochem. Biophys. 2001， 395 (1), 25-31. doi: 10.1006/abbi.2001.2569

(3) Kim, D. H.; Kim, K. H.; Kim, D. H.; Liu, K. H.; Jung, H. C.; Pan, J. G.; Yun, C. H. Generation of Human Metabolites of 7-Ethoxycoumarin by Bacterial Cytochrome P450 BM3. Drug Metab. Dispos. 2008, $36 \quad$ (11), 2166-2170. doi: $\underline{10.1124 / \mathrm{dmd} .108 .021220}$

(4) Kang, J. Y.; Ryu, S. H.; Park, S. H.; Cha, G. S.; Kim, D. H.; Kim, K. H.; Hong, A. W.; Ahn, T.; Pan, J. G.; Joung, Y. H.; Kang, H. S.; Yun, C. H. Chimeric Cytochromes P450 Engineered by Domain Swapping and Random Mutagenesis for Producing Human Metabolites of Drugs. Biotechnol. Bioeng. 2014, 111 (7), 1313-1322. doi: $10.1002 /$ bit.25202

(5) Ruettinger, R. T.; Wen, L. P.; Fulco, A. J. Coding Nucleotide, 5' Regulatory, and Deduced Amino Acid Sequences of P-450BM-3, a Single Peptide Cytochrome P450:NADPH-P-450 Reductase from Bacillus megaterium. J. Biol. Chem. 1989, 264, 10987-10995.

(6) Le, T. K.; Jang, H. H.; Nguyen, H. T.; Doan, T. T.; Lee, G. Y.; Park, K. D.; Ahn, T.; Joung, Y. H.; Kang, H. S.; Yun, C. H. Highly Regioselective Hydroxylation of Polydatin, a Resveratrol Glucoside, for One-step Synthesis of Astringin, a Piceatannol Glucoside, by P450 BM3. Enzyme Microb. Technol. 2017, 97, 34-42. doi: $10.1016 /$ j.enzmictec.2016.11.003 